\title{
Gas Treatment with Repetitive Pulsed Corona Plasmas: Experiments with Various Geometries
}

\author{
Nicolae Georgescu* Non-member
}

\begin{abstract}
A depollution system for gas treatment, using the repetitive pulsed corona plasmas, has been carried out. For the reactor chamber, various geometries are being tested: (a) point-plate; (b) wire-plate; (c) wirecylinder. To compare different geometries, the following parameters are measured or calculated: pulsed voltage; pulsed current; electrical charge per pulse; density of the corona electrons; energy dissipation by corona effect. Depending on the geometry, for $25 \sim 30 \mathrm{kV}$ maximum voltages, the density of the corona electrons is of $10^{10} \sim 10^{11} \mathrm{~cm}^{-3}$, and the energy dissipation by corona effect is of $1 \sim 100 \mathrm{~mJ}$ per pulse. Considerations concerning the geometry optimization are proposed.
\end{abstract}

Keywords: gases depollution, corona plasmas, repetitive pulses, reactor geometry

\section{Introduction}

The atmospheric pressure corona plasmas have a lot of ecological applications. We are focused on the gases depollution. For the time being, the research in this field is at a fundamental level ${ }^{(1) \sim(12)}$. The main problem is the energy efficiency of the depollution process, which must be raised up to the industrial accepted values.

The corona plasmas are produced between two or more electrodes, by applying between them DC or pulsed electrical voltages. The inter-electrodes space is used to "treat" the polluted gas with the corona electrons. The pulsed corona plasmas have some important advantages over the DC ones. If the electrical pulses have less than $1 \mu \mathrm{s}$ width, much higher electric fields can be applied, without causing spark breakdown in the reactor. The higher electric fields generate electron concentrations of order of magnitudes larger than under DC conditions. Because of the higher concentrations, space charge effects disperse electrons more uniformly throughout the reactor volume. The reactors can be thus designed with larger volumes, and this means a greater productivity of the depollution process. Also, for short corona pulses, the formed ions have a low temperature, and this means that less energy is lost for the gas heating. In this way, greater energy efficiencies may be obtained.

Our present research is using the repetitive pulsed corona plasmas especially to destroy the $\mathrm{NO}_{\mathrm{x}}(\mathrm{NO}+$ $\mathrm{NO}_{2}$ ), $\mathrm{SO}_{2}$ molecules from a polluted gas.

$\mathrm{NO}_{x}$ - responsible for acidic rain and tropospheric ozone formation - remains the most serious hazard to human health, than any other compound.

$\mathrm{SO}_{2}$ - highly soluble in water - can be easily absorbed in the upper respiratory system. Several hours exposure to $\mathrm{SO}_{2}$ levels of 1 part per million (ppm) in air may lead

\footnotetext{
* Plasma Physics and Nuclear Fusion Lab., National

Institute for Laser, Plasma and Radiation Physics

P.O.Box MG-36, Magurele, Bucharest, Romania
}

to constriction of the airways.

\section{Basic Considerations}

The present paper emphasizes the influence of the reactor geometry over its performances in the depollution process.

Three different reactor geometries (Fig.1) are being studied: (a) Point-plate; (b) Wire-plate; (c) Wirecylinder.

The conditions for both the formation and propagation of the corona electrons depend strongly on the geometric electric field. Also, the chemical performance of the corona reactor depends on the gas residence time and the type of flow (laminar or turbulent).

2.1 Electric Field Distribution If the needle point of a point-plate configuration is represented as a hyperboloid, the electric field along the needle axis can be described as ${ }^{(13)}$ :

$$
\begin{aligned}
& E(x, t)=E_{0}(t) \frac{1}{1-\frac{(d-x)^{2}}{d(r+d)}}, \cdots \cdots \ldots \ldots \ldots \\
& E_{0}(t)=\frac{V(t)}{\sqrt{d(r+d)} \ln \left(\frac{\sqrt{r+d}+\sqrt{r}+\sqrt{d}}{\sqrt{r+d}+\sqrt{r}-\sqrt{d}}\right)},
\end{aligned}
$$

where: $x$ is the distance from the needle point; $r$ is the minimum radius of curvature of the point; $d$ is the pointplate distance; $V(t)$ is the inter-electrodes voltage.

For a wire-plate configuration, the electric field is expressed for the plane of symmetry through the wire and perpendicular to the plate ${ }^{(14)}$ :

$$
E(x, t)=E_{\max }(t) \frac{r}{x+r-\frac{x^{2}}{2 d}},
$$




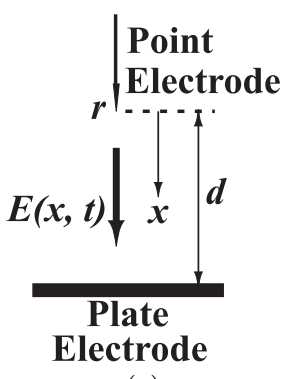

(a)

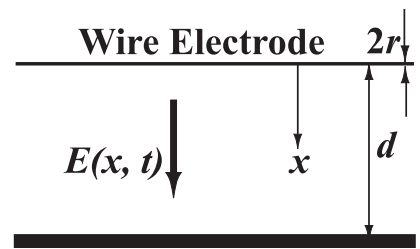

Plate Electrode

(b)

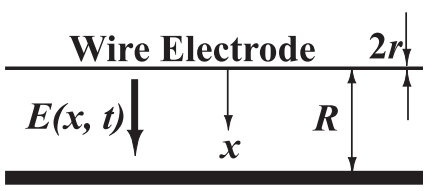

Cylinder Electrode

(c)

Fig. 1. The three studied reactor geometries: (a) Point-plate; (b) Wire-plate; (c) Wire-cylinder

$$
E_{\max }(t)=\frac{V(t) \sqrt{\left(\frac{d}{r}\right)^{2}+\frac{2 d}{r}}}{d \ln \left(1+\frac{d}{r}+\sqrt{\left(\frac{d}{r}\right)^{2}+\frac{2 d}{r}}\right)},
$$

where: $x$ is the distance from the wire; $r$ is the wire radius; $d$ is the wire-plate distance; $V(t)$ is the interelectrodes voltage.

The most simple electric field distribution is obtained with the wire-cylinder configuration, because the electric field depends on radial distance only. The radial electric field is given by:

$$
\begin{aligned}
& E(x, t)=E_{\text {max }}(t) \frac{r}{x+r}, \\
& E_{\max }(t)=\frac{V(t)}{r \ln \left(\frac{R}{r}\right)}, \cdots
\end{aligned}
$$

where: $x$ is the distance from the wire; $r$ is the wire radius; $R$ is the cylinder internal radius; $V(t)$ is the interelectrodes voltage.

In Fig. 2, the three electric field distributions are presented, for $V=27 \mathrm{kV}, r=0.25 \mathrm{~mm}, d=R=20 \mathrm{~mm}$ (these are the most used values in our experiments).

The maximum electric field is obtained in the point-plate geometry. But this is not enough. More

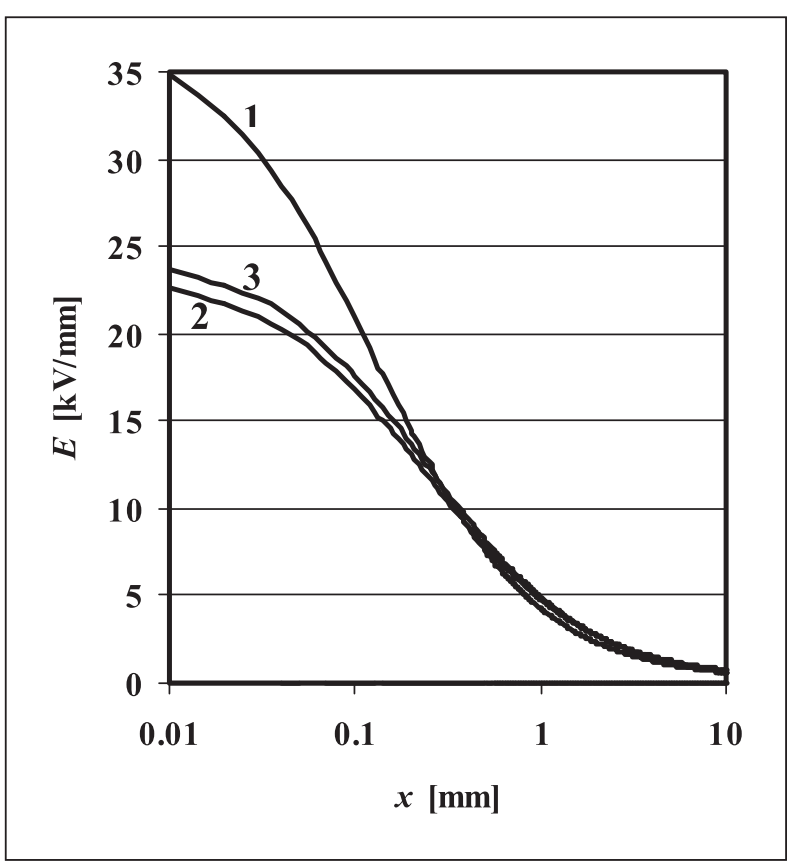

Fig. 2. Electric field distributions for the three reactor geometries: Point-plate 1; Wire-plate 2; Wire-cylinder $3, V=27 \mathrm{kV} ; r=0.25 \mathrm{~mm} ; d=$ $R=20 \mathrm{~mm}$

parameters will be analysed further, in order to decide upon an optimal geometry.

2.2 Energy Efficiency The energy efficiency for a reactor chamber is defined as:

$$
\varepsilon=W / \Delta N,
$$

where $W$ is the energy dissipated by corona effect, and $\Delta N$ is the number of the destroyed pollutant molecules.

$W$ is given by:

$$
W=w f t_{R}=w f V_{R} / q, \cdots
$$

with $w$ - the energy dissipated per pulse by corona effect; $f$ - the pulse repetition frequency; $t_{R}$ - the gas residence time in the reactor chamber; $V_{R}$ - the volume of the reactor chamber; $q$ - the gas flow rate. Also,

$$
\Delta N=N_{G A S} \Delta c=n_{G A S} V_{R} \Delta c, \cdots \cdots \cdots \cdots
$$

where $n_{G A S}$ is the molecules density of the polluted gas, and $\Delta c$ is the reduction of the concentration of the pollutant molecules, relative to the polluted gas molecules. For Normal Pressure and Temperature (NPT), $n_{G A S}=$ $2.505 \cdot 10^{25}$ molecules $/ \mathrm{m}^{3}$. A practical expression for $\varepsilon$ results if $w$ is given in [mJ/pulse], $f$ - in [pulses per second], $q$ - in [liters/min], $\Delta c$ - in parts per million [ppm], $\varepsilon$ - in $[\mathrm{eV} /$ molecule $]$ :

$$
\varepsilon=14.97 w f /(q \Delta c) .
$$

Each geometry of the reactor chamber has a given value for $\varepsilon$. For greater $\Delta c$, greater energies dissipated per pulse by corona effect must be realised. That is why $w$ is one of the main parameters we have in view, when 
the various geometries are compared.

\section{Experimental Set-up}

For gas treatment with repetitive pulsed corona plasmas, a depollution system has been carried out. Its main sub-systems are: 1 . High-voltage repetitive pulser; 2. Reactor (depollution) chamber; 3. Gas flow circuit; 4. Gas analyzer.

3.1 High-voltage Repetitive Pulser In order to produce corona plasmas, the electrical pulses must have parameters of tens of $\mathrm{kV}$ amplitude, tens up to hundreds of ns width, tens up to hundreds of A load current. The productivity of the depollution process rises with the repetition frequency of the high-voltage electrical pulses.

The high-voltage repetitive pulser discharges a capacitor in the primary of a pulse transformer. The highvoltage switch is a TGI1000/25 thyratron $(25 \mathrm{kV}, 1 \mathrm{kA}$ maximum, $1 \mathrm{~A}$ average). The capacitor is resonantly charged in the inter-pulses interval, by using a highvoltage rectifier, and an inductance-diode circuit. The pulse transformer is the key component of this subsystem. It must assure a very good magnetic coupling between the primary and the secondary winding. Many construction solutions have been tested. The best solution is a transformer with $5 \sim 10$ parallel wires, wound together on a toroidal magnetic core.

Two types of magnetic core material are used:

a. Amorphous magnetic material (Metglas 2605CO - Allied Signal Inc. - USA). The core is made of strip with $25 \mathrm{~mm}$ width and 23 microns thickness, having 4 microns of interlaminar insulation. The core dimensions are: $172 \mathrm{~mm}$ outer diameter, $110 \mathrm{~mm}$ inner diameter, $25 \mathrm{~mm}$ height.

b. Ferrite type material. The toroidal core dimensions are: $90 \mathrm{~mm}$ outer diameter, $70 \mathrm{~mm}$ inner diameter, $40 \mathrm{~mm}$ height. With 25 turns windings, highvoltage pulses with $25 \sim 100 \mathrm{~ns}$ rise-time have been obtained. The rise-time value depends of the winding connection structure, and also of the transformer ratio $(1: 2$, or $1: 3)$. For greater voltage amplitudes, a circuit with two thyratrons and two pulse transformers may be used. The pulse transformers have series connected secondaries. Taking into account a $15 \mathrm{kV}$ as a maximum anode voltage for each of the two thyratrons, pulses of up to $90 \mathrm{kV}$ amplitude could be applied on the reactor chamber.

The width of the high-voltage pulses depends of the discharging capacitor value, which can be increased in $5 \mathrm{nF}$ steps. With $10 \sim 25 \mathrm{nF}$, the pulses width is in the hundreds of nano-seconds range.

The high-voltage repetitive pulser is trigerred by a circuit which provides $1 \mathrm{kV}, 5 \mu \mathrm{s}, 5 \mathrm{~A}$ pulses for the thyratrons grids. A pulse forming line is discharged by a thyristor, the circuit being closed with the primary of a 1:2 pulse transformer. The thyristor is driven by a low power pulser, through an optical fiber connection, electrical-optical transmitter, and optical-electrical receiver (Hewlett Packard HFBR 1502, HFBR 2502, respectively).
The repetition frequency can be varied between $0 \sim 1000$ pulses per second.

The voltage pulses are measured with a capacitiveresistive divider (Tektronix, model $\mathrm{P} 6015$ ), with division ratio $1 / 1000$. Rise times in excess of 10 ns are correctly measured. For current pulses, Tektronix P6021 probe with passive termination is used. In this case, the bandwidth is $120 \mathrm{~Hz} \sim 60 \mathrm{MHz}$.

The voltage and current signals are both measured with a digital oscilloscope with $100 \mathrm{MHz}$ bandwidth and $1.25 \mathrm{GS} / \mathrm{s}$ sample rate on each channel (Tektronix TDS 3012). Data are stored using the built-in floppy disk drive.

\subsection{Reactor (Depollution) Chamber}

3.2.1 Point-plate Geometry A structure with 5 needle-electrodes has been used. The 5 needleelectrodes are uniformly spaced on a circumference with $15 \mathrm{~mm}$ diameter. The plane electrode is a $20 \mathrm{~mm}$ diameter disk. The inter-electrodes distance can be varied up to $100 \mathrm{~mm}$. All the structure is mounted in a cylindrical glass chamber, $30 \mathrm{~mm}$ internal diameter. The active volume of the reactor chamber depends on the interelectrodes distance. If this distance is $20 \mathrm{~mm}$, then the reactor volume is of $15 \mathrm{~cm}^{3}$.

3.2.2 Wire-plate Geometry A stainless steel 0.5 diameter wire is mounted above the plane electrode. The wire-plane distance can be 10, 20, 30, $40 \mathrm{~mm}$. The structure length is of $400 \mathrm{~mm}$, the same as in the wirecylinder geometry. In order to eliminate the edge effects, the plane electrode has $300 \mathrm{~mm}$ width. The reactor volume is of $320 / 480 \mathrm{~cm}^{3}$, for inter-electrodes distances of 20/30 mm respectively.

3.2.3 Wire-cylinder Geometry The central electrode is made of stainless steel ( $0.5 \mathrm{~mm}$ diameter). The outer electrode (made also of stainless steel) is a cylinder with $43 \mathrm{~mm}$ inner diameter. The chamber length - $400 \mathrm{~mm}$ - means an internal volume of $580 \mathrm{~cm}^{3}$.

3.3 Gas Flow Circuit The first experiments have been performed with dry/humid air streams. At the end of the paper, results obtained with a simulated polluted gas are presented. This gas is a mixture of $\mathrm{N}_{2}$ with 500 parts per million (ppm) $\mathrm{NO}$ and $1000 \mathrm{ppm} \mathrm{SO}_{2}$ (made by SIAD S.p.A - Italy). In the near future, this mixture will be combined with air $/ \mathrm{O}_{2}$ streams. The gas streams pass through flow controller devices made with Cole-Parmer tube flowmeters and with inserted valve cartridges. Flow rates of up to $10 \mathrm{l} / \mathrm{min}$ can be controlled and measured.

The gas mixture may be humidified by passing it through a bottle filled with water. After the humidifier, the gas mixture enters the reactor chamber. The treated gas is then analyzed in the final sub-system.

3.4 Gas Analyzer With electro-chemical sensors, the gas analyzer (KM9106 - Kane Intnl. Ltd. England) can measure concentrations of $\mathrm{NO}, \mathrm{NO}_{2}, \mathrm{SO}_{2}$, $\mathrm{CO}, \mathrm{O}_{2}$.

The analyzer probe can also measure the gas temperature (up to $650^{\circ} \mathrm{C}$ ). Data is sent to a remote handset through the connection lead and can be stored if required. All logged information can be displayed 
on the handset, downloaded to a computer (with the FIREWORKS software) or output directly to an internal printer.

\section{Experimental Results}

To compare the different geometries, the applied voltage $v(t)$, and the corresponding pulsed current $i(t)$ are being measured. The following parameters are being calculated: electrical charge per pulse; density of the corona electrons; energy dissipation by corona effect.

The electrical charge per pulse $\left(Q_{P U L S E}\right)$ is obtained by integrating the corona current in time variable. The corona current pulse $\left(i_{C}(t)\right)$ is given by:

$$
i_{C}(t)=i(t)-i_{D}(t)=i(t)-C d v / d t,
$$

where $i_{D}(t)$ is the displacement current, and $C$ is the capacitance of the reactor chamber.

It must be mentioned that the displacement current



Fig. 3. Point-plate geometry: The applied voltage (2) and the corona current pulse (1) $(5 \mathrm{kV} /$ div; 200 $\mathrm{mA} /$ div; $200 \mathrm{~ns} /$ div., $d=20 \mathrm{~mm} ; V_{R}=15 \mathrm{~cm}^{3}$ )

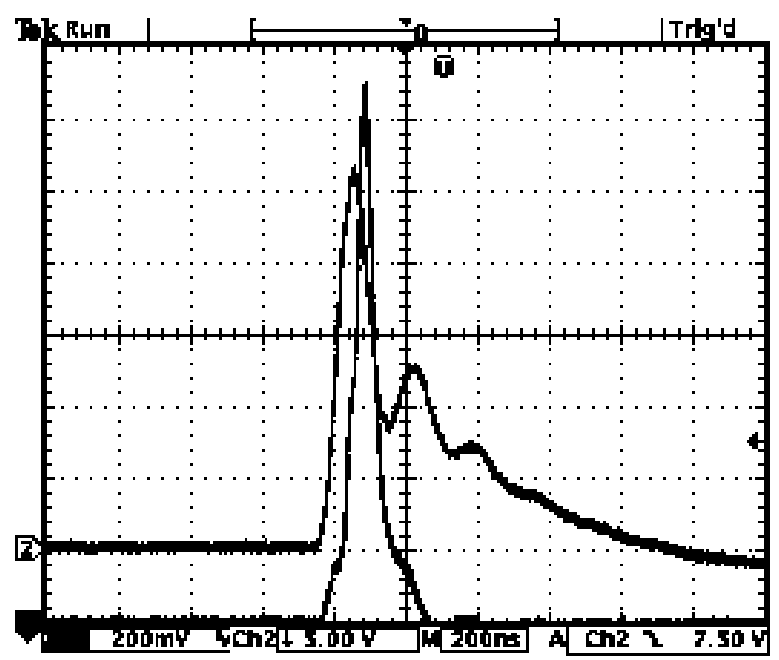

Fig. 4. Wire-plate geometry: The applied voltage (2) and the corona current pulse (1) $(5 \mathrm{kV} /$ div; 2 A/div; $200 \mathrm{~ns} /$ div., $r=0.25 \mathrm{~mm} ; d=20 \mathrm{~mm} ; V_{R}$ $=320 \mathrm{~cm}^{3}$ ) is much less than the total pulsed current. In the wirecylinder geometry, $C=5 \mathrm{pF}$ only, and $i_{D}(t)_{\max }=1 \mathrm{~A}$, for the case when the maximum value of the total pulsed current is of $56 \mathrm{~A}$. In the other geometries, the reactor chamber capacitance has much smaller values. Consequently, the displacement current keeps on being much less than the total pulsed current. Therefore, with a very good approximation, the measured pulsed currents are the corona current ones. With the electrical charge per pulse $\left(Q_{P U L S E}\right)$, the density of the corona electrons $\left(n_{E L}\right)$ is obtained.

Finally, the energy dissipation by corona effect $(w)$ is calculated as the time integral of the $v(t) \cdot i_{C}(t)$ product.

Figs. $3 \sim 6$ present typical examples of the applied inter-electrodes voltage and the corona current pulse for the three different geometries of the reactor chamber. In all cases, the maximum inter-electrodes voltage is of

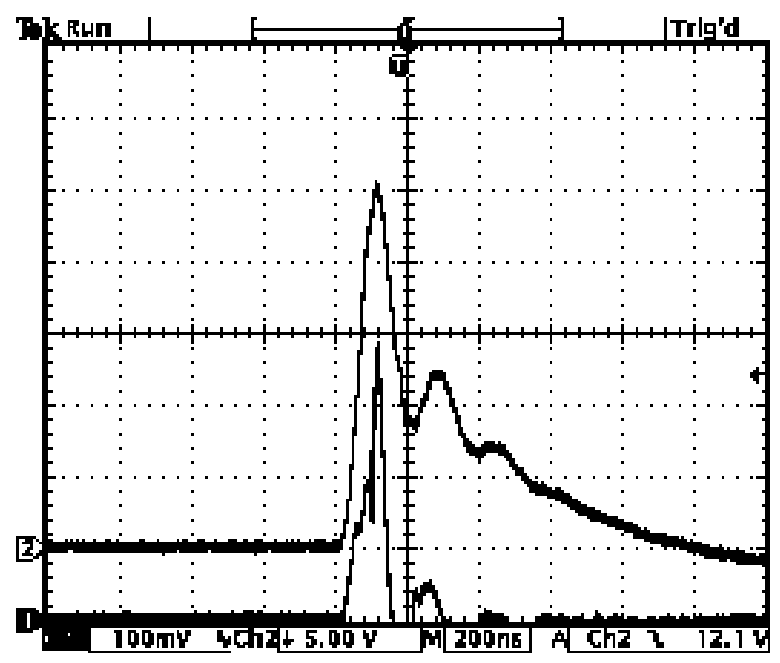

Fig. 5. Wire-plate geometry: The applied voltage (2) and the corona current pulse (1) $(5 \mathrm{kV} /$ div; 1 $\mathrm{A} /$ div; $200 \mathrm{~ns} /$ div., $r=0.25 \mathrm{~mm} ; d=30 \mathrm{~mm} ; V_{R}$ $\left.=480 \mathrm{~cm}^{3}\right)$

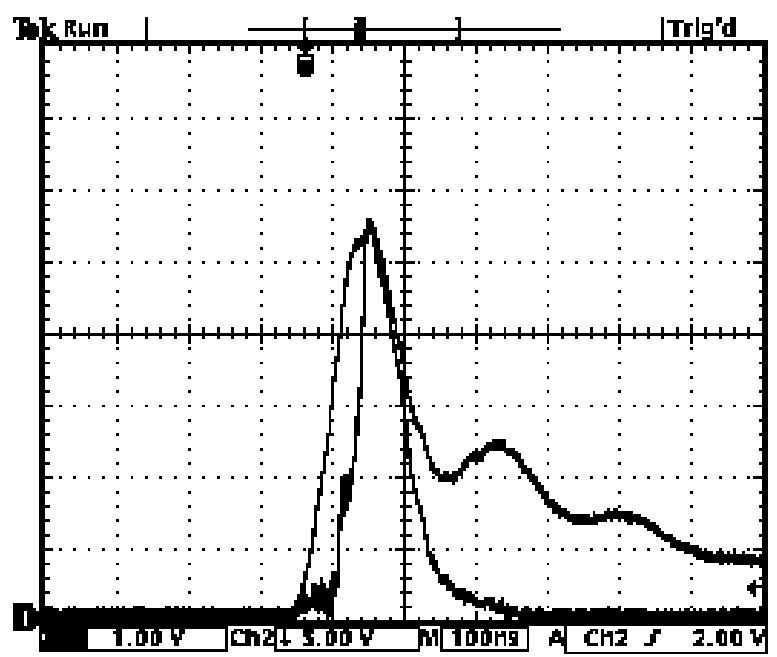

Fig. 6. Wire-cylinder geometry: The applied voltage and, within it, the corona current pulse (5 $\mathrm{kV} /$ div; $10 \mathrm{~A} /$ div; $100 \mathrm{~ns} /$ div. $r=0.25 \mathrm{~mm} ; R$ $=21.5 \mathrm{~mm} ; V_{R}=580 \mathrm{~cm}^{3}$ ) 
Table 1. Main results obtained with various geometries, in the depollution experiments with repetitive pulsed corona plasmas

\begin{tabular}{|c|c|c|c|c|c|}
\hline Geometry & $\begin{array}{c}I_{\max } \\
{[\mathrm{A}]}\end{array}$ & $\begin{array}{l}Q_{P U L S E} \\
{\left[10^{12} \mathrm{e}\right]}\end{array}$ & $\begin{array}{c}n_{E L} \\
{\left[10^{10} \mathrm{~cm}^{-3}\right]}\end{array}$ & $\begin{array}{l}t_{R} \\
{[\mathrm{~s}]}\end{array}$ & $\begin{array}{c}w \\
{[\mathrm{~mJ} / \text { pulse }]}\end{array}$ \\
\hline Point-plate & 1.56 & 1.00 & 6.6 & 0.5 & 1.7 \\
\hline $\begin{array}{l}\text { Wire-plate- } 1 \\
(d=20 \mathrm{~mm})\end{array}$ & 14.80 & 9.25 & 2.9 & 10.0 & 16.3 \\
\hline $\begin{array}{l}\text { Wire-plate-2 } \\
(d=30 \mathrm{~mm})\end{array}$ & 4.40 & 2.75 & 0.6 & 15.0 & 9.7 \\
\hline Wire-cylinder & 56.00 & 31.50 & 5.4 & 18.0 & 85.0 \\
\hline $\begin{array}{l}V_{\max }=27 \mathrm{k} \\
I_{\max }-\max \\
Q_{P U L S E}- \\
n_{E L}-\text { mear } \\
t_{R}-\text { residen } \\
\text { gas flow rat }\end{array}$ & $\begin{array}{l}\text { num c } \\
\text { lectric } \\
\text { densit } \\
\text { e time }\end{array}$ & $\begin{array}{l}\text { orona curre } \\
\text { y charge p } \\
y \text { of the cor } \\
\text { of the gas }\end{array}$ & $\begin{array}{l}\text { at; } \\
\text { r corona curre } \\
\text { ona electrons; } \\
\text { inside the reac }\end{array}$ & $\begin{array}{l}\text { nt pul } \\
\text { tor cha }\end{array}$ & $\begin{array}{l}\text { e; } \\
\text { amber, }\end{array}$ \\
\hline
\end{tabular}

$27 \mathrm{kV}$, and the positive corona effect is produced.

In Fig. 3, for a point-plate geometry $(20 \mathrm{~mm}$ interelectrodes distance, $15 \mathrm{~cm}^{3}$ the reactor volume), the maximum corona current is relatively low - $1.56 \mathrm{~A}$. However, because of the small reactor volume, the mean density of the corona electrons has the greatest value: $6.6 \cdot 10^{10}$ electrons $/ \mathrm{cm}^{3}$. But this value must be considered together with the residence time of the gas in the reactor chamber - 0.5 seconds only, for $2 \mathrm{l} / \mathrm{min}$ flow rate. This means a low energy efficiency of the depollution process. Another disadvantage is the great spatial non-uniformity of the corona electrons.

Fig. 4 and Fig. 5 present the results for the wireplate geometry, with inter-electrodes distance of $20 \mathrm{~mm}$ and $30 \mathrm{~mm}$ respectively. There is a great difference in corona current value, in the favour of the $20 \mathrm{~mm}$ distance: $14.8 \mathrm{~A}$ in Fig. 4, and 4.4 A only in Fig. 5. For the optimum inter-electrodes distance $(20 \mathrm{~mm})$, the density of the corona electrons is of $2.9 \cdot 10^{10} \mathrm{~cm}^{-3}$. The gas residence time in the reactor chamber has a rather acceptable value: 10 seconds, for the same gas flow rate as in the point-plate geometry. Structures with more wires between parallel plates might be used ${ }^{(15)}$, but mechanical construction problems may be rather difficult.

The wire-cylinder geometry gives the best set of results. In Fig. 6, the maximum current is of $56 \mathrm{~A}$, meaning a corona electrons density of $5.4 \cdot 10^{10} \mathrm{~cm}^{-3}$. The residence time is of 18 seconds, and the energy dissipated by corona effect is of $85 \mathrm{~mJ}$ per pulse. In the same time, there is a good spatial distribution of the corona electrons inside the reactor chamber. All these considerations lead us to the conclusion that the wirecylinder geometry is the optimum one, at least for the present.

Table 1 presents the main results obtained with the three geometries. In all experiments, the maximum inter-electrodes voltage is of $27 \mathrm{kV}$.

Table 1 corresponds to the first experiments, with air streams. In the next experiments, the mixture of $\left[\mathrm{N}_{2}+(500 \mathrm{ppm} \mathrm{NO})+\left(1000 \mathrm{ppm} \mathrm{SO}_{2}\right)\right]$ has been used. With the wire-cylinder geometry, the energy dissipated per pulse by corona effect was greater than
$100 \mathrm{~mJ}$. For a pulse repetition frequency $f=20$ pulses per second, and a gas flow rate $q=2 \mathrm{l} / \mathrm{min}$, the NO concentration decreased by $\Delta c=260 \mathrm{ppm}$. Taking into account these values, the energy efficiency is less than $60 \mathrm{eV}$ per NO molecule.

\section{Conclusion}

In order to decide upon an optimal geometry, a set of parameters must be analyzed, simultaneously. The most important parameters are: the mean density of the corona electrons, the energy dissipated per pulse by corona effect, the gas residence time inside the reactor chamber. The experiments presented in this paper demonstrate that the wire-cylinder geometry has a lot of advantages, when compared with other geometrical structures.

\section{Acknowledgment}

The author thanks Dr. Monica Magureanu and Dr. Bogdan Mandache for giving the possibility to study the point-plate reactor chamber, and also for valuable discussions and comments.

This project is supported by Romanian Ministry of Education and Research, under contract number CERES1 - 139.

(Manuscript received Oct. 20, 2003, revised April 28, 2004)

\section{References}

(1) E. M. van Veldhuizen and W. R. Rutgers: "Pulsed positive corona streamer propagation and branching", J. Phys. D: Appl. Phys., Vol.35, pp.2169-2179 (2002)

( 2 ) T. Hammer: "Non-thermal plasma application to the abatement of noxious emissions in automotive exhaust gases", Plasma Sources Sci. Technol., Vol.11, pp.A196-A201 (2002)

(3) F. Fresnet, G. Baravian, L. Magne, S. Pasquires, C. Postel, V. Puech, and A. Rousseau: "Influence of water on NO removal by pulsed discharge in $\mathrm{N}_{2} / \mathrm{H}_{2} \mathrm{O} / \mathrm{NO}$ mixtures", Plasma Sources Sci. Technol., Vol.11, pp.152-160 (2002)

(4) A. Khacef, J. M. Cormier, and J. M. Pouvesle: "NO$x$ remediation in oxygen-rich exhaust gas using atmospheric pressure non-thermal plasma generated by a pulsed nanosecond dielectric barrier discharge", J. Phys. D: Appl. Phys., Vol.35, pp.1491-1498 (2002)

( 5 ) H. H. Kim, K. Takashima, S. Katsura, and A. Mizuno: "Lowtemperature $\mathrm{NO}_{x}$ reduction processes using combined systems of pulsed corona discharge and catalysts", J. Phys. D: Appl. Phys., Vol.34, pp.604-613 (2001)

(6) S. Liu and M. Neiger: "Excitation of dielectric barrier discharges by unipolar submicrosecond square pulses", J. Phys. D: Appl. Phys., Vol.34, pp.1632-1638 (2001)

( 7 ) K. Toda, K. Takaki, S. Kato, and T. Fujiwara: "Removal of $\mathrm{NO}$ and $\mathrm{NO}_{x}$ using a multipoint-type dielectric barrier discharge at a narrow gap", J. Phys. D: Appl. Phys., Vol.34, pp.2032-2036 (2001)

(8) A. Yehia, A. Mizuno, and K Takashima: "On the characteristics of the corona discharge in a wire-duct reactor", J. Phys. D: Appl. Phys., Vol.33, pp.2807-814 (2000)

( 9 ) E. A. Filimonova, R.H. Amirov, H. T. Kim, and I. H. Park: "Comparative modelling of $\mathrm{NO}_{x}$ and $\mathrm{SO}_{2}$ removal from pollutant gases using pulsed-corona and silent discharges", J. Phys. D: Appl. Phys., Vol.33, pp.1716-1727 (2000)

(10) J. Y. Park, I. Tomicic, G. F. Round, and J. S. Chang: "Simultaneous removal of $\mathrm{NO}_{x}$ and $\mathrm{SO}_{2}$ from $\mathrm{NO}-\mathrm{SO}_{2}-\mathrm{CO}_{2}-\mathrm{N}_{2}-\mathrm{O}_{2}$ gas mixtures by corona radical shower systems", J. Phys. D: Appl. Phys., Vol.32, pp.1006-11 (1999) 
(11) M. A. Jani, K. Takaki, and T. Fujiwara: "Streamer polarity dependence of $\mathrm{NO}_{x}$ removal by dielectric barrier discharge with a multipoint-to-plane geometry", J. Phys. D: Appl. Phys., Vol.32, pp.2560-2567 (1999)

(12) T. Oda, T. Kato, T. Takahashi, and K. Shimizu: "Nitric oxide decomposition in air by using nonthermal plasma processing with additives and catalyst", IEEE Trans. Industry Appl., Vol.34, pp.268-272 (1998)

(13) P. Jacottet: "Das Electrische Feld der Spitze-PlatteFunkenstrecke", Electrotechnische Zeitschrift (ETZ-A), Vol.95, pp.402-404 (1974)

(14) E. Kuffel, W. S. Zaengl: High voltage engineering - Fundamentals, p.498, Pergamon Press, Oxford (1984)

(15) D. Wang, K. Fujiya, T. Namihira, S. Katsuki, and H. Akiyama: "Diesel exhaust control using a magnetic pulse compressor", Proc. 14th IEEE International Pulsed Power Conference, Dallas, TX, USA (2003)
Nicolae Georgescu (Non-member) was born in Bucharest,

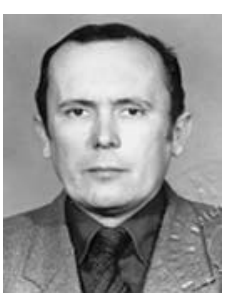

Romania, on August 3, 1947. He received a $\mathrm{Ph}$. D. degree in technical physics from Institute of Atomic Physics, Bucharest, in 1995, and is presently a Senior Scientist at National Institute for Laser, Plasma and Radiation Physics. He has worked on pulsed power technology with applications in the field of electron accelerators, high-power lasers, high magnetic fields, dense magnetized plasmas, gases/water depollution. He is a member of the Romanian Physics Society. 